James M. Wilson, M.D., Ph.D.

Director

University of Pennsylvania

Institute for Human Gene Therapy

204 Wistar

3601 Spruce Street

Philadelphia, PA 19104

United States

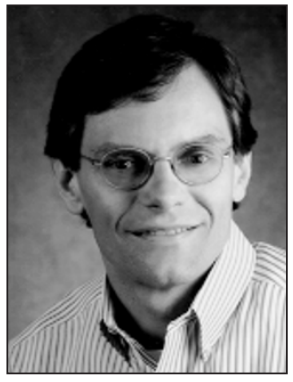

1973-1977

B.A., Chemistry, Albion College, Albion, MI

1977-1984

Ph.D., Biological Chemistry, University of Michigan Medical School, Ann Arbor, MI

1977-1984 M.D., University of Michigan Medical School, Ann Arbor MI

1984-1986 Internship and Residency, Medical Services, Massachusetts General Hospital, Boston, MA

1986-1988 Postdoctoral Fellow, Whitehead Institute, Massachusetts Institute of Technology, Cambridge, MA

1988-1993 Assistant Professor to Associate Professor, Internal Medicine and Biological Chemistry, University of Michigan

1988-1993 Assistant Investigator, Howard Hughes Medical Institute, University of Michigan

1991-1993 Chief, Division of Molecular Medicine and Genetics, University of Michigan

1993-present John Herr Musser Professor and Chair, Molecular and Cellular Engineering, University of Pennsylvania, Philadelphia, PA

1993-present Director, Institute for Human Gene Therapy, University of Pennsylvania

1993-present Professor of Medicine and Chief, Division of Medical Genetics, University of Pennsylvania

1993-present Professor at the Wistar Institute, University of Pennsylvania

Honors

1976

1977-1980

$1980-1984$

1982

1983

1984

1984

1984

1989

1990

1991

1992

1992

1993

1998

1998
Phi Beta Kappa, Albion College

National Science Foundation Predoctoral Fellowship, University of Michigan

Fellow in the Medical Scientist Training Program, University of Michigan

Thomas Francis, Jr. Memorial Award, March of Dimes University of Michigan Student Achievement Award Medical Scientist Training Program Award for Excellence Dean's Award for Research Excellence

William Dodd Robinson Award for Excellence in Internal Medicine

Young Investigator's Award, Central Society for Clinical Research

Hickman Lecturer, Central Society for Clinical Research Jerome W. Conn Award for Distinguished Research by a Junior Faculty Member

Henry Russell Award for Outstanding Faculty Member,

Distinguished Alumni Award, Albion College

Philadelphia Business Journal Health Care Heroes Award

Maurice Hilleman-Merck Research Laboratories Lecturer

of the American Society for Virology

Keynote Speaker, Albion College Opening Convocation University of Michigan

\section{Constitutive and Regulated Expression in the Systemic Delivery of Erythropoietin Following Skeletal Muscle Transduction with DNA Viral Vectors}

One of the objectives in our laboratory is to develop a system for regulated expression of recombinant genes encoding therapeutic secreted proteins from vectors injected into muscle. Adenoviral and adeno-associated viral vectors expressing erythropoietin or growth hormone from constitutive promoters were used to transduce skeletal muscle in mice with subsequent application to rhesus monkeys. Peak expression from adenoviral vectors is much higher than with AAV although it is less stable. In monkeys, serum erythropoietin from adenoviral vectors dropped 3-4 logs over the course of 1 year while that from AAV dropped only 4 -fold over 11/2 years. For regulated expression of erythropoietin, mice and rhesus monkeys were administered two previously described rAAV vectors (Science 283, 88-91; 1999). One vector constitutively expresses two chimeric proteins. These proteins are biologically inactive until they form a complex mediated by the presence of rapamycin. This ternary drug-protein complex functions as a transcriptional activator recognizing a unique DNA binding site present on the second vector upstream of the erythropoietin cDNA. Erythropoietin expression is controlled by dose and frequency of rapamycin administration. Six monkeys have received the described regulated expression system. In four monkeys, two cycles of rapamycin inducible expression have been observed with subsequent extinction of induction after 100 days following vector administration. One monkey has continued to show regulated expression of erythropoietin over 300 days with 9 cycles of intermittent drug administration while the other monkey has undergone 11 cycles of pharmacologic regulated erythropoietin expression for over 400 days. Our data support the feasibility of pharmacologically regulated transgene expression in primates. Mechanisms to explain heterogeneity in the stability of the regulated system in non-human primates is under evaluation. We are also developing modified vectors to improve the efficiency of the regulated system and screening analogs of rapamycin with superior safety profiles. 